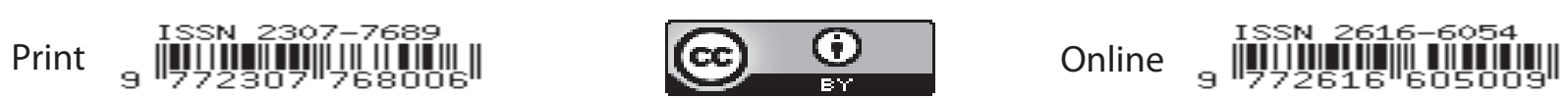

Mediscope

REVIEW ARTICLE

\title{
Suicide kills more peoples than any form of violence
}

\author{
A Sadek ${ }^{1}$, AMA Anam ${ }^{2}$, MSA Rashid ${ }^{3}$, EB Akber ${ }^{4}$, NT Khan ${ }^{5}$
}

\begin{abstract}
"Suicide is a tragic global public health problem. Globally, WHO said the death toll from suicide at almost one million people per year - accounts for half of all violent deaths. Estimates suggest fatalities could rise to 1.5 million by 2020 . Recently it's been a great concern to examine suicide trends among teenage people. They are emotional and can't tolerate difficult situation. They think it is a permanent problem so suicide is the only solution. Last year (2017) large number of SSC candidate students committed suicide in different districts due to not getting expected result. So this is the time to create awareness among society and also family support to child, otherwise no one can predict it. One day these victims will be their family members. Our review articles focuses on causes, risk factors and prevention of teenage suicide in country.
\end{abstract}

Key words: suicide, teenage, causes, risk factor \& prevention.

\section{Introduction:}

The word suicide derived from Latin word "suicidum" which means "to kill oneself". This is the act of human being intentionally causing his/ her own death. A number of factors are associated with the risk of suicide including as frustration, poverty, and socioeconomic factors. While external circumstances, such as a traumatic event, may trigger suicide but it does not seem to be an independent cause. Thus suicides are more likely to occur during periods of socioeconomic, family and individual crisis. [1] Nowadays, suicidal attempts are widely regarded as an important health problem. It has been found in recent years that majority of suicides occur among men and in younger age groups. It is estimated that over one lakh one million people commit suicide in the world every year. According to $\mathrm{WHO}, 2014$ a report titled "Preventing suicide state that across the globe, more people die from suicide than in warfare. Bangladesh ranked 10th on the list; with nearly eight suicides for every 100,000 people.[2] It is a leading cause of death among teenagers and adults under thirtyfive.[3] The rate of suicides is sharply increasing in Bangladesh, according to data from Police headquarters. In 2017, 11,095 people committed suicide in Bangladesh, which means, on an average, 30 people kill themselves every day. Barisal topped the list in 2017 , with a total of 2,585 deaths by suicide. According to data from Police Headquarters,

1. A Sadek, Associate professor \& Head Department of Forensic Medicine \& Toxicology, Army medical college, Chittagong.

2. AMA Anam, Associate professor \& Head Department of Forensic Medicine \& Toxicology, Dhaka community medical college, Dhaka

3. MSA Rashid, Assistant professor \& Head Department of Forensic Medicine \& Toxicology, AICHI medical college, Dhaka

4. EB Akber, Associate professor \& Head Department of Forensic Medicine \& Toxicology, Army medical college, Comilla.

5. NT Khan, Associate professor \& Head Department of Forensic Medicine \& Toxicology, Z H Sikder womens Medical College, Dhaka 
among the 11,095 people who committed suicide in 2017,569 of them hanged themselves, 3,467 took poison, and 59 people set themselves on fire. In 2016, the total number of suicide in Bangladesh was 10,600. In 2017, the number increased to 11,095 . The rate of suicide is increasing each year, which was shown figure $1 \&$ Table 1.[2]

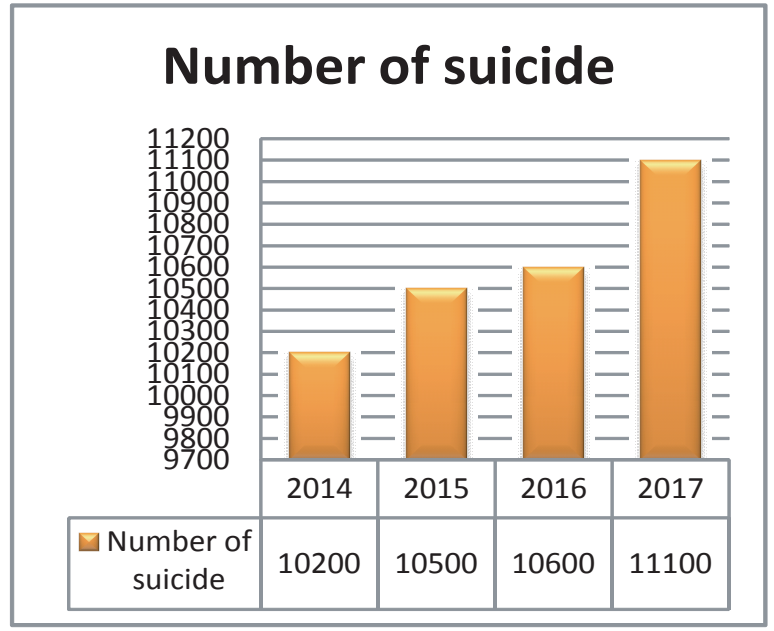

Figure 1: Suicidal rate in Bangladesh from 2014-2017

In 2015, 10,500 people committed suicide while in 2014, this number was 10,200 . It is notable that, in Bangladesh, the number of suicides is higher than the number of murders every year. In 2014, the number of murders was 4,594 but number of suicides was 10,200 . Similarly, in $2015,4,036$ people were murdered while 10,500 people committed suicide. In 2016, total 3,591 murders were reported in Bangladesh while in 2017, 3,549 people were murdered. After Barisal, Dhaka district had the highest number of suicides in 2017 . That same year, 2,585 people committed suicide in Dhaka, 1,433 people in Rangpur, and 1,197 in Sylhet. In 2017, a total of 1,239 suicide cases were reported alone in the Railway Range (areas falling under the jurisdiction of Bangladesh Railways) areas of the country. When compared with districts, the number of suicide in Railway Range area, after Barisal and Dhaka, is more than any other district.

\begin{tabular}{|c|c|c|c|}
\hline \multicolumn{4}{|c|}{ Bangladesh : number of Suicide in 2017} \\
\hline Range & $\begin{array}{c}\text { Hanged } \\
\text { themselve } \\
s\end{array}$ & $\begin{array}{c}\text { Poisoned } \\
\text { themselve } \\
s\end{array}$ & $\begin{array}{c}\text { Set } \\
\text { Themselv } \\
\text { es on Fire }\end{array}$ \\
\hline Dhaka & 1467 & 465 & None \\
\hline Chittagong & 430 & 182 & 1 \\
\hline Sylhet & 705 & 426 & 4 \\
\hline Khulna & 335 & 87 & 2 \\
\hline Barisal & 1608 & 871 & 6 \\
\hline Rajshahi & 302 & 159 & 1 \\
\hline Rangupur & 943 & 485 & 5 \\
\hline Railway & 862 & 361 & 8 \\
\hline
\end{tabular}

Table 1 : Bangladesh: Number of suicide in 2017

Day by day it is creating an alarming sign for the society. Young person who will lead the nation one day, their unexpected death is a great loss for the country. In our medical literature this type of articles are published rarely. Suicide rate higher in women than men in our country, which is shown in Table 2

\begin{tabular}{|c|c|c|}
\hline \multicolumn{3}{|c|}{$\begin{array}{l}\text { Suicide more prevalent among women } \\
\text { than men }\end{array}$} \\
\hline Year & Male & Female \\
\hline 2014 & 198 & 367 \\
\hline 2015 & 126 & 223 \\
\hline 2016 & 178 & 367 \\
\hline 2017 & 194 & 417 \\
\hline Total & 696 & 1374 \\
\hline
\end{tabular}

Table 2: Bangladesh society for the enforcement of Human rights (source)

In 2018 SSC results published, increased death tool, which made concern every person. According to news reports and hospital sources, there have been 70 cases of suicides reported all over Bangladesh (except Dhaka) from January to April 2018. In Dhaka, the Dhaka Medical College Hospital recorded 35 cases of suicide, and a further 10 were reported in the city. In the suburbs around Dhaka city, another 10 were also reported. But police and medical authorities alike say that the numbers are much deflated against real numbers, which could be several times higher. These actual number increases if scrutinized door to door. Causes of teenage suicide can be difficult to detect and may involve several factors. Teens go through a 
vulnerable period at this stage in their lives. No matter how small or big their problems, their troubles may feel unbearable or overwhelming. Noticeable changes in behavior, such as withdrawal from friends and family or violent and aggressive behavior, are among the many signs of potential teen suicide, but parents and mental health care providers also need to understand the causes of suicide in teens for effective prevention. Suicide is the second leading cause of death - following motor vehicle accidents - among teenagers and young adults. On average, adolescents aged 15 to 19 years have an annual suicide rate of about 1 in 10,000 people. Among youths 12 to 16 year of age, up to $10 \%$ of boys and $20 \%$ of girls have considered suicide. The teen years are an anxious and unsettling period as boys and girls face the difficulties of transition into adulthood. It is a period in life that is often confusing, leaving teens feeling isolated from family or peers. [4]Unfortunately, some may at one point or another perceive suicide as a permanent answer to problems that are more often than not just temporary. The self doubts, confusion, and pressures to succeed or conform can come at a high price for troubled adolescents. Girls generally attempt suicide more often than boys, but boys are about 4 times more likely to die from the suicide attempt. This is because the methods that boys choose - often using poisons or hanging - are more lethal than those chosen by girls, namely drug overdoses or cutting themselves.

\section{Causes of Teen Suicide}

Minors choose death because suffering becomes intolerable as per their perception. Peer pressure, social and academic pressure, turmoil in the family can lead to emotional breakdown, feeling of loneliness, rejection, failure to handle loss, and poor performance. They feel that there is little hope for change, improvement, or possibility of a better future with the life that they experience. Most of the teen suicidal attempts are the resultant of their inability to handle depression effectively, though there are many other factors that can lead one to take such an extreme step. One study says, "In teenagers, depression is considered a major - if not the leading - cause of teen suicide." [ 5]

Factors and risks contributed to youth suicide are academic pressure, alcohol consumption, the loss of a valued relationship, frequent change of residency, and poor family patterns. [6]

- Genetics and family history: Most of the time, a history of suicidal tendencies in the family or an attempted suicide may be responsible for teen suicides. Researchers find that genes are also responsible for such thoughts and behavior, which can be passed down across generations. Research also finds that, children with low levels of serotonin (a hormone in the brain that balances mood) are prone to emotional disturbances, aggressive behavior, and suicide. [7]

- Disharmony in the family: Major fights in the family and divorce of parents can emotionally drain the child. He/she may not be able to accept or balance the situation, leading to depression. Aggression in families and its transference can be one of the main causes of transmission of suicidal tendencies in families. [8]

- Unhealthy, abusive relationships or a breakup: Teen years can be most stressful and in a way, relationships or breakups can affect the emotional stability. Dealing with a heartbreak can be tough for them. Low self-esteem and depression too, lands teenagers in abusive and unhealthy relationships, which may lead to suicide. [9]

- Alcohol or drug abuse: Children resort to alcohol and drugs to lighten their worries and problems. However, in no time the addiction leaves them feeling vulnerable and helpless, leading to suicidal thoughts. 
- Feelings of anger and guilt: Stress and feelings of rejection, loneliness, feeling unwanted, can affect the child mentally. This may result in aggressive behavior or extreme mood swings. Often the guilt of doing something wrong, or hurting someone may force the teen to end his/her life.

- Physical or mental disorders: A psychological disorder, mental illness, or depression can trigger suicidal thoughts in teenagers. As per data, 95 percent people had an ongoing mental illness or disorder, when they committed suicide. Most teens who attempt suicide do so because of depression, bipolar disorder or borderline personality disorder. These disorders amplify the pain a teen may feel. It is because of this that any suicidal teen should be treated by a medical profession.

- Poor academic performance: Family pressure, expectations to excel, and competition put pressure on teens. They may not be able to live up to these expectations and hence suicide may appear to be the only solution to their problems. [11]

- Sibling rivalry: The introduction of a new member in the family may not be taken sportingly by the child. Sudden shift of love and care towards the sibling may not be taken positively by the child. The very thought of sharing the family's love can also make the teen feel neglected and unwanted. Hatred towards the sibling may also lead to emotional imbalance.

- History of suicide and exposure: If the teen has known a person, friend, or family member who has committed suicide, it can push an already depressed and disturbed child towards talking this extreme step. Fiction stories, news, and any other source that exposes the child to a suicide attempt may be risky. Previous exposure to suicide through parental attempts have also been found to have a 3.5 increase in a youth's probability of having suicidal thoughts, with a 2.6 increased chance of them attempting suicide. [12]

- Physical and emotional abuse: A troubled childhood, mental, physical, or sexual abuse and harassment can affect their emotional balance. In most cases they cannot deal with the aftermath and trauma.

- Experience of a personal loss: Teenagers may not be able to cope with the sudden loss of a dear one, which may give rise to suicidal thoughts and feelings in them.

- Social and other issues: Those who are bisexual or homosexual may fall prey to suicidal thoughts mainly due to social pressure, status, community, and family issues. Stress-related factors like exposure to a new or uncomfortable environment, problem adjusting in a social circle, bullying, and peer pressure can also lead to anxiety and depression.

\section{Warning signs and risk factors:}

To prevent and curb suicide, it is important for parents and friends to notice and understand the symptoms and signs. Counsel the child before it drives him to take an extreme decision. Expression of feelings related to depression and worthlessness definitely means something is seriously wrong. These symptoms may be present together or in varied combinations, and can be addressed effectively if noticed earlier. Check for the following signs: [13]

\section{Risk Factors:}

- Mental illness/psychiatric diagnosis

- Family history of suicide and/or exposure to suicide Family history of mental illness

- Physical/sexual abuse

- Losses

- Aggressive behavior/impulsivity

- Lack of social support/social isolation

- Poor coping skills

- Access to ways of harming oneself, like drugs, knives, etc.

- Difficulties in dealing with sexual orientation 
- Physical illness

- Family disruptions (divorce or problems with the law)

- Traumatic event

\section{Warning Signs:}

- Preoccupation with death (e.g., recurring themes of death or self-destruction in artwork or written assignments

- Intense sadness and/or hopelessness

- Not caring about activities that used to matter

- Social withdrawal from family, friends, sports, social activities

- Substance abuse

- Sleep disturbance (either not sleeping or staying awake all night)

- Giving away possessions

- Risky behavior

- Lack of energy

- Inability to think clearly/concentration problems

- Declining school performance/increased absences from school

- Increased irritability

- Changes in appetite

\section{Suicidal prevention}

One can help prevent adolescent suicide by discouraging isolation, addressing a child's depression which is correlated with suicide, getting rid of any objects that a child could use to commit suicide and simply paying attention to what the child does or feels. [14] .Helping a suicidal teen starts with recognizing the warning signs and taking them seriously. In case of any doubt, parents and friends should not hesitate to talk to them and ask questions directly. Chances are he/she will open up to you and look up to you for help with assurance.

Immediate consultation with a mental health professional is a must in extreme to moderate cases. Most of the time the cause is depression, however depending on the age, sensi tivity, psychological illnesses (if any), overall health, nature, severity, and the number of symptoms and signs, a treatment can be chalked out. An in-depth psychological evaluation with appropriate medications followed up in a timely manner is necessary. Local support groups should be made available to teens so that they can reach someone in emotional crisis. [15]

" Along with treatment, the primary need is to care, value, and respect the child.

» Most teen suicides can be prevented by effective communication and psychotherapy.

» Do not leave the child lonely, and let there be more than one person he can turn to for help.

" Never take their talks lightly, there are many instances where the suicidal person has given hints to a friend or family before taking the extreme step. So, don't think if they talk they will never do it.

» One should pay attention to the postdepressive period, when the individual looks near normal, yet it could be an unsafe period.

" Assure him that such feelings are temporary and will surely pass.

" Keep weapons like guns, blades, and medication away from his reach. According to data, almost in 60 percent of the total suicide cases victims have used guns to kill themselves.

» Agree to help the person whenever he wishes to share his feelings.

» Do not argue or find faults. The fact that someone is helping him figure out a way to betterment has a healing effect on him.

\section{Conclusion:}

Suicides are preventable. Parents, teachers, and friends should always are on the side of caution and safety. Parents should watch over their teenagers and help them clear their 
Mediscope 2019;6(2):87-92

distortions about life and bring back hope and vigor. Trust me, no magical spells are needed, help them open up and express whatever they feel. Even the deepest of depression is curable, and people with suicidal thoughts and behavior can be treated with timely care and concern. Help them embrace a new life with your efforts. Schools are a great place to provide more education and support on suicide prevention. Since students spend a majority of their time at school, school can be either a haven from or a source of suicidal triggers and students' peers can heavily influence their state of mind. The school setting is an ideal environment to educate students on suicide and have support readily available

\section{References:}

1. Hawton K, van Heeringen K. . "Suicide". Lancet 373 (9672): April 2009, p-137281.

2. https://www.dhakatribune.com/opinion/ special/2018/05/08/examining-alarmingsuicide-trends-bangladeshDhka tribune.

3. CIS: UN Body Takes On Rising Suicide Rates - Radio Free Europe / Radio Liberty 2006".

4. Adolescent Suicide: https://medbroadcast.com/condition/getc ondition/adolescent-suicide

5. Teen Suicide Causes and Issues," Retrieved 2012-04-26 : http:// www.teensuicidestatistics.com/causesissues.htm

6. Kastenbaum, Robert j. (2012).Death, society and Human Experience. Boston: Pearson.pp. 199-200. ISBN978-0-20500108-8.
7. Teenage Suicide: https:// psychologenie.com/ causes-of-teenagesuicide

8. Hawton, K, Saunders, K.E.,\& O'Conor, R.C. (2012). Self-harm and suicide in adolescents. The Lancet, 379(9834), 23732382

9. When Your Partner Threatens Suicide : https://www.loveisrespect.org/content/wh en-your-partner-threatens-suicide/

10. Mental illness as a cause of teen suicide : https://www.healthyplace.com/suicide/wh $y$-do-teens-commit-suicide-causesof-teen-suicide

11. Poor academic performance: https://www.medicalbrief.co.za/ archives/poor-academic-performancepredictor-suicide-risk/

12. Niederkrotenthaler, Thomas. "Exposure to Parental Mortality and Markers of Morbidity, and the Risks of Attempted and Completed Suicide in Offspring: an Analysis of Sensitive Life Periods". Journal of Epidemiology and Community Health. 66 (3): 233-239.

13. Suicide in Teens and Children Symptoms \& Causes http://www.childrenshospital.org/ conditions- and-treatments/ conditions/s/ suicide-and-teens/ symptoms-andcauses

14. Teen suicide: What parents need to know - Mayo Clinic"www.mayoclinic.org. Retrieved 2016-10-26

15. CDC : https:// www.cdc.gov/health communication/toolstemplates/ entertainmented /tips/ SuicideYouth.html 